\title{
Exerting an impact on clinical practice-upholding quality, visibility, and timeliness of publications
}

\author{
Martin CS Wong, MD, MPH \\ Editor-in-Chief, Hong Kong Medical Journal
}

Hong Kong Med J 2017;23:4-5

DOI: 10.12809/hkmj175063

Since its inception in 1995, the Hong Kong Medical Journal has evolved to have an official impact factor in the Journal Citation Report, and it continues to be a flourishing academic journal. Over the last 6 years, the number of articles we received has increased by $52 \%$ to 440 in 2016, and the total number of nonlocal articles submitted has risen drastically by $320 \%$. This is a true reflection of the journal's increasing popularity in the clinical and academic communities. The acceptance rate has decreased from $50 \%$ to less than $30 \%$, reflecting the inevitably more rigorous and stringent criteria applied in the evaluation of all submissions. Our heartfelt gratitude goes to the capable and visionary leadership of our past Editorsin-Chief, Dr CK Lee, Dr YL Yu, Dr Richard Kay, and Prof Ignatius $\mathrm{Yu}$ who have undoubtedly laid a solid foundation for our Journal. We are also appreciative of the relentless efforts of our editorial members and reviewers, both locally and internationally, who have jointly made the journal to be one with growing prestige and quality.

In previous inaugural and valedictory editorials by our past Editors-in-Chief, ${ }^{1-5}$ the importance of articles making an impact, whether on clinical practice, public health policy or future research, has been repeatedly emphasised. I believe this still holds very true as it is an ultimate aspiration of all authors who are determined to publish their original works. One major question remains to address-how can we make our published articles more influential? As the new Editorial Board is appointed, we have in mind three important criteria that we consider crucial: quality, visibility, and timeliness of publication.

We are most interested in articles that are of high methodological quality. To further make this a top priority in the coming years, the editorial team will place an increasing weight on the quality of the research methodology when they make editorial decisions. The peer reviewer report has been modified to ensure this is an overriding criterion for article acceptance. In particular, we have solicited more support from senior members of the Editorial Board, together with the our epidemiology and biostatistics advisors, to rigorously review and clarify the methodological details of all provisionally accepted original articles well before they are

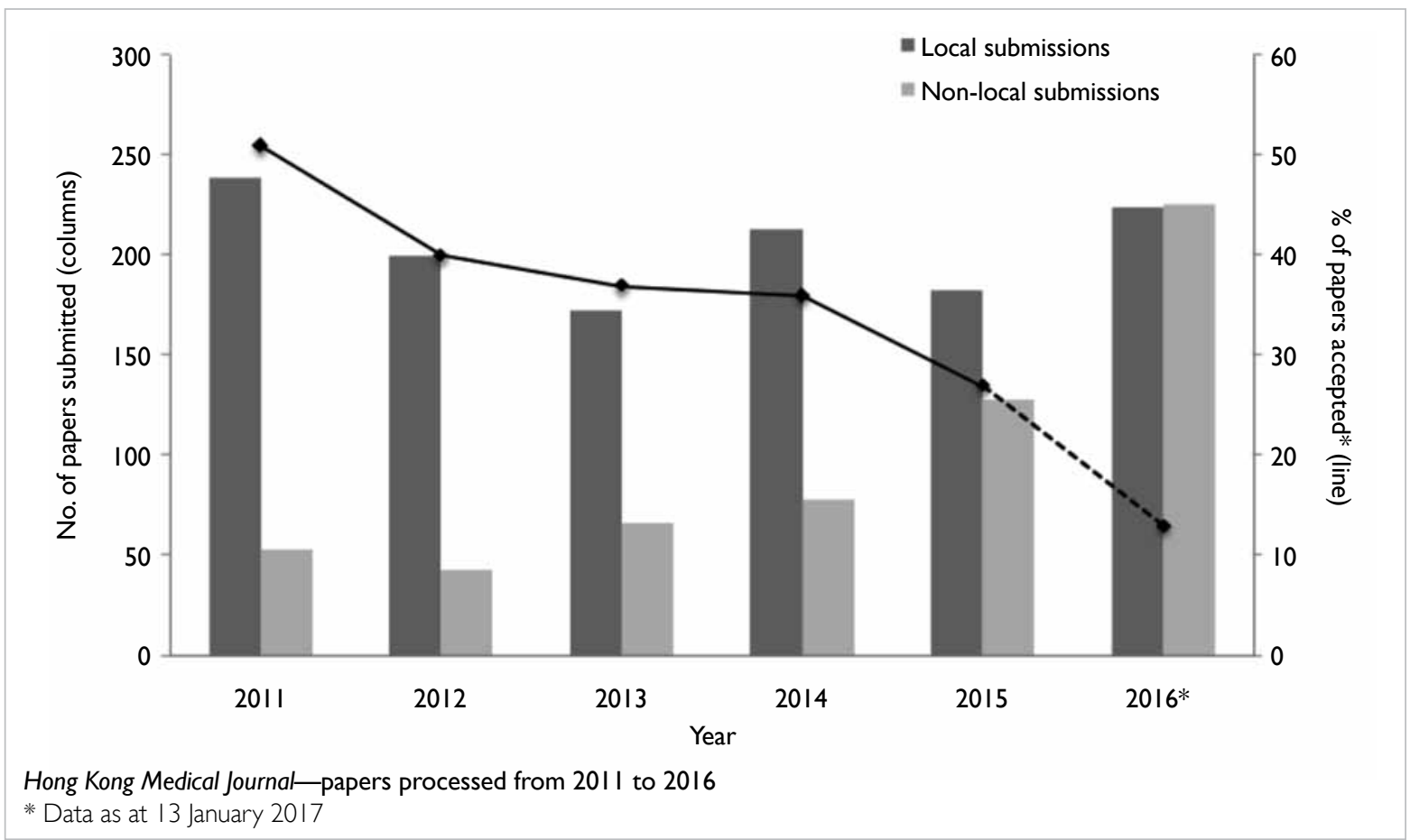


formally published. We hope that this process will help strengthen the validity and presentation of the information we publish. Apart from original research papers, we solicit high-quality reviews as well as medical practice papers that describe recent technological advances or summarise current guidelines for addressing common medical problems. We hope these papers will help readers in their daily practice.

Another important aspect of our future work is to enhance the visibility of our journal articles. Without effective dissemination, no high-quality articles can realise their actual impact. The initiative began in 2015 when a responsive, user-friendly, web technology was built to enhance browsing of the journal via desktops, smartphones, and tablets. The "online first" feature of the publication since 2013 is yet another attempt to make our articles easily accessible. Our senior editors will also offer advice for authors to make their articles more "search engine optimised" 6 by suggesting potential modifications to the keywords of all original contributions as displayed in MEDLINE versions. We do of course recommend that our authors present their findings at academic conferences, share them with their colleagues and appropriate social media, and expand their professional network.

Timely publication is a crucial aspect, and indeed responsibility, of every academic journal to ensure efficient dissemination of research findings. In the coming years, our editorial members will be working towards the target of making the first editorial decision of whether to send a paper for external peer review within an average of 15 working days for all original articles. Whilst this requires very diligent and committed work from all Editorial Board members, we believe this initiative is worthwhile.
Authors as well as readers will welcome the reduced time between acceptance of a manuscript and its appearance in our Journal via expeditious review.

We strongly believe that HKMJ will continue to be an internationally world-class academic journal that publishes articles of "high quality reflecting the current practice in the science and art of medicine and public health". ${ }^{5}$ We are also confident that the Journal will continue the proud history over 32 years of the Journal of the Hong Kong Medical Association and its predecessors in "providing a useful source of medical information on advances in medical research and clinical practice." ${ }^{5}$ To this end, we must emphasise that the continuing support of our international advisors, board members, editorial staff, reviewers, authors, and all Academy Fellows is essential. To quote our Immediate Past Editor-in-Chief Prof Ignatius Yu, we sincerely "call on your continued love and support" ${ }^{2}$ to make the Journal a great success. We are always attentive and appreciative of your invaluable comments, and of course your submissions.

\section{References}

1. Yu IT. Helping the Hong Kong Medical Journal and Hong Kong to advance their impact on medical practice. Hong Kong Med J 2016;22:524-5.

2. Yu IT. Calling on your continued love and support. Hong Kong Med J 2011;17:4.

3. Yu YL. Building upon a firm foundation. Hong Kong Med J 2001;7:4.

4. Kay R. Valedictory remarks. Hong Kong Med J 2010;16:420.

5. Lee JC, Yu YL. Inaugural editorial. Hong Kong Med J 1995;1:4.

6. Burger M. How to improve the impact of your paper. Available from: https://www.elsevier.com/authors-update/ story/publishing-tips/how-to-improve-the-impact-ofyour-paper. Accessed 29 Dec 2016. 